\title{
Comparison of efficacy of azithromycin plus levamisole versus azithromycin alone in the treatment of moderate to severe acne
}

1) Dr. Ammara Naseer MBBS, FCPS. Assistant Professor, Dermatology Department, Bakhtawar Amin Medical and Dental College, Multan

2) Dr. Ahsan Farooq MBBS. Ex-House Officer, Dermatology Department, Nishtar Medical University and Hospital, Multan

3) Dr. Javed Iqbal MBBS, FCPS. Assistant Professor, Dermatology Department, Nishtar Medical University, Multan

4) Dr. Ghulam Mujtaba MBBS, FCPS. Professor, Dermatology Department, Nishtar Medical University, Multan

Author of correspondence: Dr. Ammara Naseer MBBS, FCPS

Assistant Professor, Dermatology Department, Bakhtawar Amin Medical and Dental College, Multan, House number 113 CB, Street number 3 Jameelabad near Airport road Multan Cantt.

Email: emaildrammara@gmail.com Phone: 0614506460

\begin{abstract}
Objective To compare the efficacy of azithromycin plus levamisole versus azithromycin alone in the treatment of moderate to severe acne.

Patients and methods Ninety patients with moderate to severe acne were divided into two groups. Group A was given oral azithromycin 500mg/day, three days a week, plus oral levamisole $150 \mathrm{mg}$ /day, two days a week and group B was given oral azithromycin 500mg/day, three days a week. Patients were followed up at $4^{\text {th }}$ and $8^{\text {th }}$ week for efficacy and tolerability.

Results Efficacy of treatment in Group A (given azithromycin plus levamisole) was seen in $36(80 \%)$ patients while in Group B (oral azithromycin alone) efficacy was seen in $27(60 \%)$ patients (p-value $=0.048)$.

Conclusion Combination therapy with oral azithromycin plus levamisole is more efficacious as compared to oral azithromycin alone in the treatment of moderate to severe acne vulgaris.
\end{abstract}

Key words Acne, azithromycin, levamisole.

DOI: $10.7176 / \mathrm{JMPB} / 58-05$

Publication date: August $31^{\text {st }} 2019$

\section{Introduction}

Acne vulgaris is a common inflammatory disease of the follicular portion of the 
pilosebaceous units. ${ }^{1}$ It is characterized by seborrhea, the formation of open and closed comedones, erythematous papules and pustules and in more severe cases nodules, deep pustules and pseudocysts. ${ }^{2}$ It is a common dermatological disease affecting almost $80 \%$ of adolescents, $4 \%$ of adult men and $13 \%$ of women. ${ }^{3}$

The precise mechanisms of acne are not known but there are four major pathogenic factors:

1. Increased sebum production

2. Hypercornification of pilosebaceous duct

3. Abnormal bacterial function

4. Production of inflammation

In addition multiple genetic and environmental factors as well as neuropeptides play a role, with inflammation serving as a central nidus. Propionibacterium acnes (P.acnes) has a strong pro-inflammatory activity and targets molecules involved in innate cutaneous immunity, keratinocytes and sebaceous glands of the pilosebaceous follicles. ${ }^{4}$ The microorganisms residing on the skin surface are attracted to lipid rich optimal environment inside the hair follicles. Here, the bacteria rapidly multiply inducing a local inflammatory response by releasing chemotactic substances and attracting polymorphonuclear leukocytes to the site of inflammation. ${ }^{5}$ The innate immune system recognizes $P$. acnes via toll-like receptor 2 leading to secretion of inflammatory cytokines. ${ }^{6}$ The adaptive immune response also has a central role in inflammation. ${ }^{6}$

Treatment of acne depends on the type and severity of disease and includes topical and oral medications. Topical compounds are retinoids, benzoyl peroxide and antibiotics while antibiotics, isotretinoin and cyproterone acetate are commonly used oral compounds. ${ }^{7}$ Halting the inflammatory cascade by either the antibiotics or immune-modulating agents should offer promise in the treatment of acne meanwhile reducing the sequels of disease. Azithromycin is an oral antibiotic and levamisole is an immune-modulating agent, both of which act to surcease inflammation. Side effects of azithromycin include nausea, pain abdomen, diarrhea, vomiting and drug fever while use of levamisole is associated with milder gastrointestinal side effects of nausea and diarrhea and serious central nervous system side effects and allergic reactions are very rare. ${ }^{8}$

Limited data are available regarding clinical features, consequences and response of acne vulgaris to the therapy in Asian skin types. The present study aimed to compare the efficacy of azithromycin plus levamisole with azithromycin alone in the treatment of moderate to severe acne.

\section{Materials and methods}

The study was conducted at Dermatology Department, Nishtar Hospital, Multan. Total duration of study was six months (from $11^{\text {th }}$ October 2015 to $10^{\text {th }}$ April 2016). A total of 90 patients of 18 to 35 year age group of both genders having moderate to severe acne with a global acne score of 19 to 38 for less than 3 months duration were included. Pregnant and lactating females, patients already taking anti acne therapy for last one month or more, those with drug induced acne and those with deranged liver function tests (LFTs) and renal function tests (RFTs) were excluded. Global acne grading system (GAGS) is a quantitative scoring system in which the total severity score is derived from summation of six regional sub-scores [Figure 1]. 
Written informed consent was taken prior to enrollment of patients. They were randomly allocated into two study groups, A and B, by lottery method, with forty five patients in each group. Group A was given oral azithromycin $500 \mathrm{mg} /$ day, three days a week, plus oral levamisole $150 \mathrm{mg} /$ day, two days a week. ${ }^{8}$ Group B, also having 45 patients was given oral azithromycin $500 \mathrm{mg} /$ day, three days a week. ${ }^{8}$ Patients were followed up on every $4^{\text {th }}$ week and side effects were noted. On $8^{\text {th }}$ week of treatment efficacy was assessed.

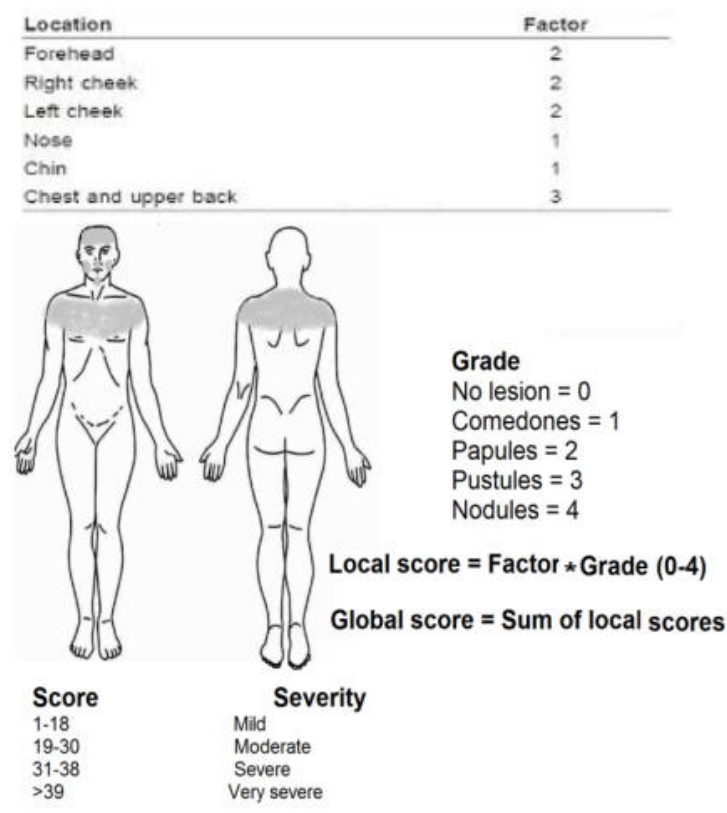

Figure 1 The Global acne grading system

Efficacy of both the treatments was assessed by calculating pre and post treatment global acne score. More than or equal to $50 \%$ reduction of global acne score from baseline was labeled as efficacious response whereas with less than $50 \%$ reduction of global acne score from baseline treatment was labeled as non-efficacious.

\section{Results}

Of 90 patients, $62(68.89 \%)$ were females and $28(31.11 \%)$ were males with female to male ratio of 2.5:1. Mean age of patients in group A was $27.93 \pm 4.7$ years and in group B it was $27.8 \pm 4.72$ years. Mean weight of patients in group A was $74.13 \pm 7.8 \mathrm{~kg}$ and in group B it was $72.7 \pm 8.1 \mathrm{~kg}$. Mean duration of disease in group A was $6.24 \pm 3.2$ weeks and in group B it was $6.53 \pm 3.34$ weeks. Mean Body Mass Index (BMI) of patients in group A was $27.7 \pm 3.69 \mathrm{~kg} / \mathrm{m}^{2}$ and in group B it was $27.2 \pm 3.92 \mathrm{~kg} / \mathrm{m}^{2}$ [Table 1]. Efficacy of treatment in Group A (given azithromycin plus levamisole) was seen in $36(80 \%)$ patients while in Group B (oral azithromycin alone) efficacy was seen in $27(60 \%)$ patients $(P$ value $=0.048)$ [Figure 3]. No serious side effects were noted in both groups. A very few people of either group reported nausea and diarrhea which resolved on its own with the continuation of treatment. 
Table 1 Mean age, weight, disease duration, BMI of patients, gender and global acne scores of patients undergoing treatment

\begin{tabular}{|l|l|l|}
\hline Variables & Group A & Group B \\
\hline Mean age (years) & $27.93 \pm 4.7$ & $27.8 \pm 4.72$ \\
\hline Gender & $15(33.3 \%)$ & $13(28.9 \%)$ \\
Male & $30(66.6 \%)$ & $32(71.1 \%)$ \\
\hline $\begin{array}{l}\text { Mean weight of patients }(\mathrm{kg}) \\
\text { Mean duration of disease }(\mathrm{weeks})\end{array}$ & $74.13 \pm 7.8$ & $72.7 \pm 8.1$ \\
\hline Mean BMI of patients $\left(\mathrm{kg} / \mathrm{m}^{2}\right)$ & $6.24 \pm 3.2$ & $6.53 \pm 3.34$ \\
\hline Global acne scores & $27.7 \pm 3.69$ & $27.2 \pm 3.92$ \\
\hline Moderate acne (score $18-30)$ & 16 & 31 \\
\hline Severe acne (score $31-38)$ & 29 & 14 \\
\hline
\end{tabular}

Acne, a very common disease of adulthood and as it affects the face, the lesions of acne cause much cosmetic concern and psychological distress. It was originally thought that the lesions developed after abnormal exfoliation of the keratinocytes lining the sebaceous follicles, leading to hypercornification and development of a microcomedone. However, as the research and technology advanced, there has been a paradigm shift with regard to understanding the pathogenesis of acne which is now viewed as a primary inflammatory skin disorder. ${ }^{9}$ Current data suggests that $P$. acnes plays a central role in inflammation. $P$. acnes is a gram-positive anaerobic bacteria that is normally found in the sebaceous follicle. Increased numbers of $P$. acnes are commonly found in the follicles of acne patients and reduction in these counts correlates with clinical improvement in acne patients. Accordingly, antimicrobial agents and antibiotics have been a mainstay of acne therapy targeting $P$. acnes colonies. Antibiotic resistance to $P$. acnes is increasing ${ }^{10}$ due to various factors, such as biofilm production by $P$. acnes and the inability of $P$. acnes to be killed or ingested by neutrophils and macrophages. The biofilm excreted by $P$. acnes is a glycocalyx polymer and may contribute to its persistence and immunogenicity. ${ }^{11} P$. acnes releases various cytokines which modulate T-helper cell 1/T-helper cell 2 (Th1/Th2) responses in acne patients. The role of oral antibiotics in acne is mainly by addressing the colonization of $P$. acnes while adding levamisole will therefore increase the efficacy by regulating immune system. 

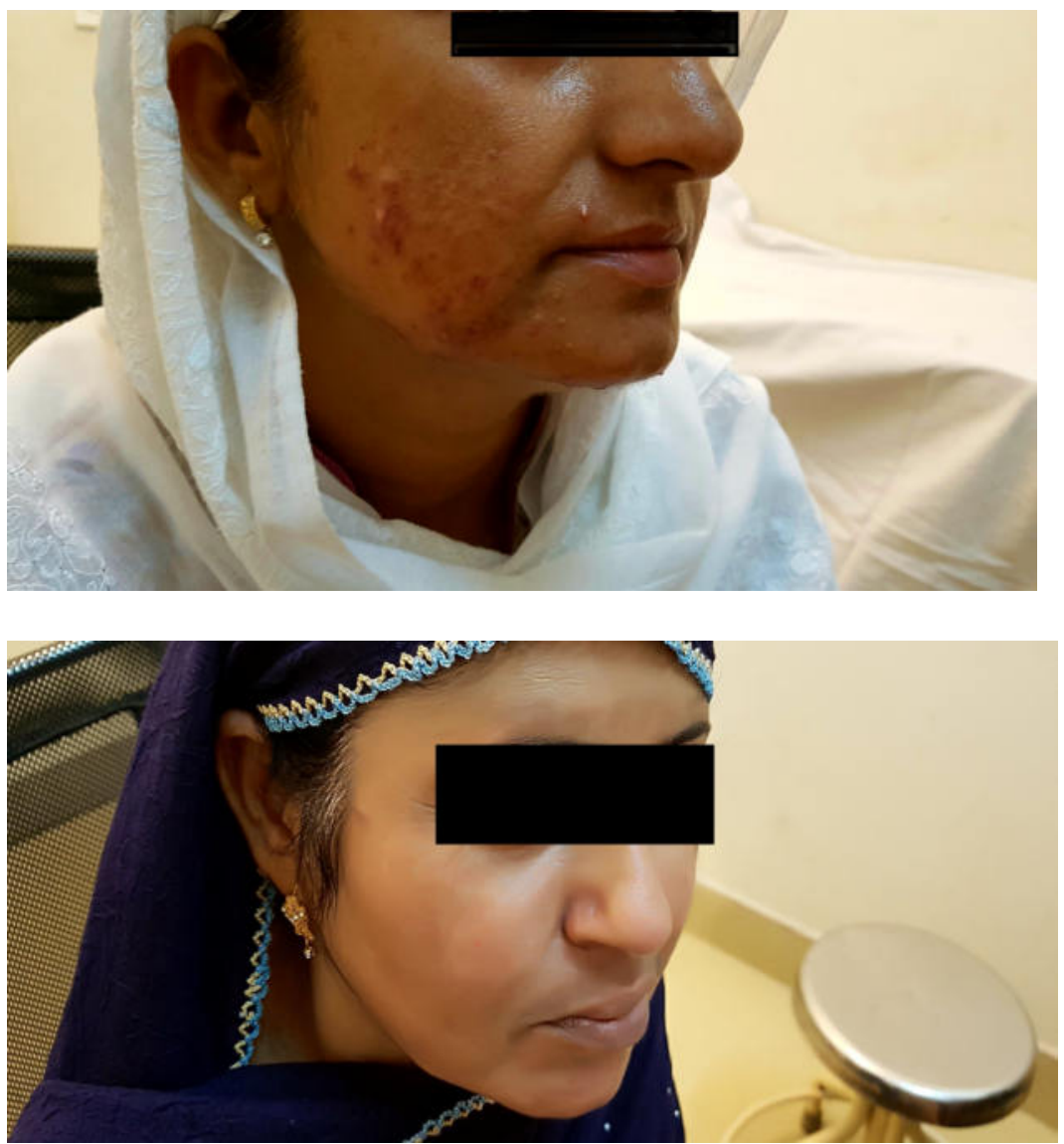

Figure 2 Improvement in acne at the end of 8 week treatment with azithromycin plus levamisole

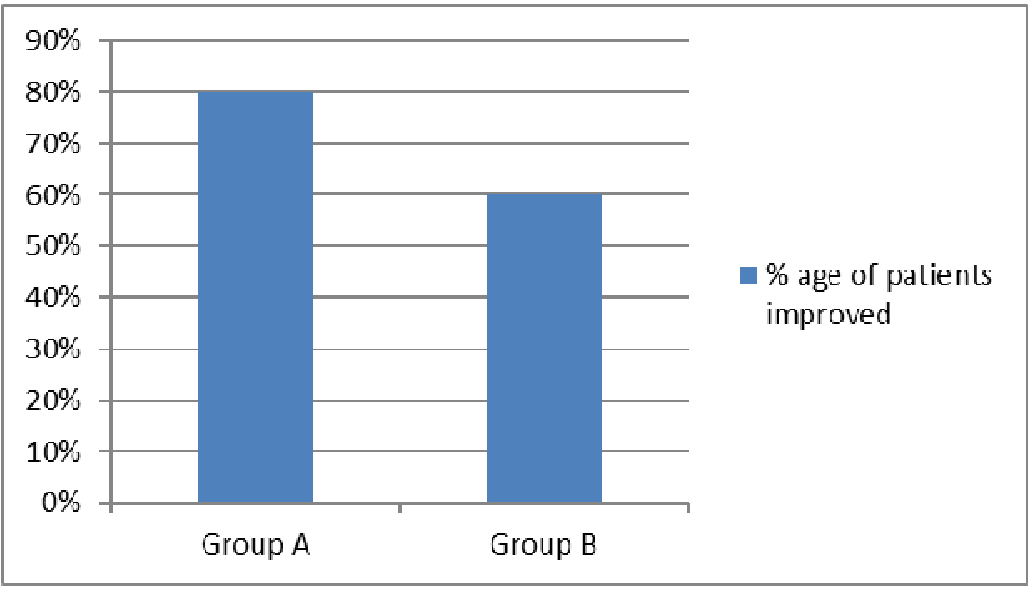

Figure 3 Comparison of percentages of patients improved after treatment in both groups 


\section{Discussion}

A research carried out in the dermatology clinic of Rasoul-e-Akram Hospital in Tehran, Iran in 2006 demonstrated that combination treatment with doxycycline and levamisole yielded greater reduction in lesion count than doxycycline alone so it was concluded that when used as an adjuvant with other drug such as oral antibiotics, levamisole acting synergistically is an effective treatment for severe non-responsive acne vulgaris. ${ }^{12}$

A study conducted at Ahvaz Jundishapur University of Medical Sciences in Iran in 2011 has demonstrated that combination of azithromycin and levamisole resulted in $76.93 \%$ and $82.35 \%$ reduction of papules, pustules and nodulocystic lesions vs $69.32 \%$ and $57.99 \%$ with azithromycin alone. These two studies showed better response with levamisole as an adjuvant to antibiotics compared to antibiotics alone.

Our study compared azithromycin plus levamisole with azithromycin alone in the treatment of moderate to severe acne patients. It was seen that those who received combination of azithromycin and levamisole showed $80 \%$ response and those who were given azithromycin alone showed $60 \%$ response. The effectiveness of both groups was compared using chi-square test and $P$ value was found to be 0.048 showing that there is a significant difference $(P$ value $\leq 0.05)$ in the efficacy of both groups.

\section{Conclusion}

Our study concluded that azithromycin plus levamisole combination therapy is more efficacious as compared to azithromycin alone in the treatment of moderate to severe acne vulgaris. So, this combination therapy of azithromycin and levamisole can be opted as a better treatment modality as this regime makes the treatment more acceptable, cost effective, with an acceptable safety profile because of lower incidence of dose related side effects.

\section{References}

1. Koo EB, Petersen TD, Kimball AB. Meta-analysis comparing efficacy of antibiotics versus oral contraceptives in acne vulgaris. J Am Acad Dermatol. 2014;71:450-9.

2. Layton AM. Disorders of sebaceous glands. In; Burns T, Breathnach S, Cox N, Griffiths C. Rook's Textbook of Dermatology. $8^{\text {th }}$ ed. UK: Wiley-Blackwell; 2010. 42.17.

3. Ten JK, Jones E, Allen E, Pripoteny S, Raza A, Wolfe B. Evaluation of essential clinical components and features of current acne global grading scales. J Am Acad Dermatol. 2013;69:754-61.

4. Beylot C, Auffret N, Poli F, Claudel JP, Leccia MT, Del Giudice P, et al. Propionibacterium acnes: an update on its role in the pathogenesis of acne. J Eur Acad Dermatol Venereol. 2014;28:271-8.

5. Kistowska M, Meier B, Proust T, Feldmeyer L, Cozzio A, Kuerdig T, et al. Propionibacterium acnes promotes Th17 and Th17/Th1 responses in acne patients. J Invest Dermatol. 2015;135:110-8. 
6. Agak GW, Qin M, Nobe J, Kim MH, Krutzik SR, Elashoff D, et al. Propionibacterium acnes induces an IL-17 response in acne vulgaris that is regulated by vitamin A and vitamin D. J Invest Dermatol. 2014;134:366-73.

7. Dreno B, Bettoli V, Ochsendrof F. An expert view on the treatment of acne with systemic antibiotics and/or isotretinoin in the light of new European recommendations. Eur J Dermatol. 2006;15:565-71.

8. Rassai S, Mehri M, Yaghoobi R, Sina N, Mohebbipour A, Feily A. Superior efficacy of azithromycin plus levamisole vs azithromycin in the treatment of inflammatory acne vulgaris: an investigator blind randomized clinical trial on 169 patients. Int J Clin Pharmacol Ther. 2013;51:490-4.

9. Kircik LH. Advances in the understanding of the pathogenesis of inflammatory acne. J Drugs Dermatol. 2016;15:7-10.

10. McCarty M. Evaluation and management of refractory acne vulgaris in adolescent and adult men. Dermatol Clin. 2016;34:203-6.

11. Achermann Y, Tran B, Kang M, Harro JM, Shirtliff ME. Immunoproteomic identification of in vivoproduced Propionibacterium acnes proteins in a rabbit biofilm infection model. Clin Vaccine Immunol. 2015;22:467-76.

12. Ansarin H, Savabynasab S, Behzadi AH, Sadigh N, Hasanloo J. Doxycycline plus levamisole: combination treatment for severe nodulocystic acne. J Drugs Dermatol. 2008;7:737-40. 